\title{
Gluten content of imported gluten-free foods: national and international implications
}

\section{Geoffrey M Forbes' ${ }^{1}$ Kenneth Dods ${ }^{2}$}

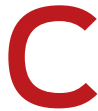

oeliac disease (CD) is the only common disease for which strict dietary compliance is the sole treatment. Sensitivity to gluten varies between patients with $\mathrm{CD}$, so that restricting levels in food to under one part per million ( $\mathrm{ppm}$ ) would protect the maximum number of patients. ${ }^{1}$ In a daily diet of $500 \mathrm{~g}$ food, $1 \mathrm{ppm}$ is equivalent to $0.5 \mathrm{mg}$, the amount in $1 / 5000$ of a slice of wheat flour bread containing $2.5 \mathrm{~g}$ gluten.

International food codes require that foods labelled "gluten-free" (GF) contain less than $20 \mathrm{ppm}$ gluten; in Australia and New Zealand, however, a "no detectable gluten" standard applies. ${ }^{2-4}$ Current laboratory techniques have a reporting limit of $1 \mathrm{ppm}$, and a detection limit of $0.5 \mathrm{ppm}$ gluten in food. We assessed the compliance of imported GF-labelled foods with the local food standard, as well as the international capacity of industry to comply with Australian standards, given commercially available analytical reporting and detection limits.

A total of 169 GF-labelled food items manufactured overseas were purchased from four retailers in Perth, Western Australia. The countries of origin were in Europe (nine countries), Asia (nine), and North (two) and South America (five); the food categories included crackers, bread and biscuits (41 items), cereals, flour and grains (37), condiments and sauces (30), spices (21), pasta (16), drinks and soups (15), and confectionary and snacks (nine).

We used a sandwich enzyme-linked immunosorbent assay (ELISA) gliadin detection kit (ESGLISS-48, ELISA Systems). Testing complied with strict food chemistry testing protocols: five variable concentration calibration standards and blank solution tests were used, calibration standards performance was confirmed every 15 samples, internal control materials were employed, and duplicate random samples (1 in 10) from each ELISA plate were tested. All positive results were confirmed on a stored original food sample.

Gluten was detected in 24 of 169 products $(14 \%)$, of which 20 had unquantifiable but detectable levels $(<1 \mathrm{ppm})$ and four had quantifiable levels (three, $1.0 \mathrm{ppm}$; one, $1.1 \mathrm{ppm}$ ). Gluten was detected in products supplied from each of the four continents and from each food category (except pasta and drinks/soups).

Our findings, in conjunction with those of 2008 and 2010 surveys of foods mostly produced in Australia, ${ }^{5}$ have three important implications. Firstly, people with CD can confidently consume GFlabelled products purchased in Australia. Secondly, a marked tightening of international GF standards is readily achievable by industry; the gluten levels in the foods we analysed were all below $1.5 \mathrm{ppm}$, less than one-tenth of the standard set by the Codex Alimentarius of $<20 \mathrm{ppm}^{2}$ Thirdly, we recommend that authorities revise the current Australian GF standard of "no detectable gluten" ${ }^{\prime \prime}$ to " $\leq 1 \mathrm{ppm}$ ", as it is not practical or reasonable for industry to comply with the stricter standard. In our survey, $14 \%$ of products were non-compliant with the current Australian standard, but none contained more than $1.1 \mathrm{ppm}$ gluten.

Competing interests: No relevant disclosures.

(c) 2016 AMPCo Pty Ltd. Produced with Elsevier B.V. All rights reserved.
1 Office of Food Safety, Center of Food Safety and Applied Nutrition, Food and Drug Administration. Health hazard assessment for gluten exposure in individuals with celiac disease: determination of tolerable daily intake levels and levels of concern for gluten. May 2011. http://www.fda. gov/downloads/Food/FoodScienceResearch/ UCM264152.pdf (accessed Apr 2016).

2 Food and Agriculture Organization of the United Nations, World Health Organization. Standard for foods for special dietary use for persons intolerant to gluten
(Codex Alimentarius Standard 118-1979). Revised 2008. http://www.fao.org/fao-who-codexalimentarius/ sh-proxy/en/?lnk=1\&url=https $\% 253 \mathrm{~A} \% 252 \mathrm{~F} \% 252$ Fworkspace.fao.org\%252Fsites\%252Fcodex\%252 FStandards\%252FCODEX\%2BSTAN\%2B118-1979\%252 FCXS_118e_2015.pdf (accessed Apr 2016).

3 Association of European Coeliac Societies. AOECS standard for gluten-free foods. Brussels: AOECS, 2015. http://www.aoecs.org/downloads/AOECS\%20Standard \%20November\%202015.pdf (accessed Apr 2016).
4 Australian Government. Australia New Zealand Food Standards Code. Standard 1.2.8. Nutrition information requirements Federal Register of Legislation, F2015L00395. Mar 2016. http://www.comlaw.gov.au/ Details/F2012C00218 F2015L00395 (accessed July 2016).

5 NSW Food Authority. Presence of gluten in foods labelled "gluten-free" (NSW/FA/CP047/1101). Mar 2011. http://www.foodauthority.nsw.gov.au/_Documents/ scienceandtechnical/gluten_survey_report_2011.pdf (accessed Apr 2016). 